\title{
Assessment Quality of Sleep in Patients undergoing Hemodialysis
}

\author{
Marwa Moustafa Mahmoud ${ }^{1}$, Shalabia Elsayed AboZead ${ }^{2}$, Walaa Hosny Mohammad ${ }^{3}$, Hanan Abd El- \\ Razik Abd El-all ${ }^{4}$ \\ 1. B.Sc.Ng, Faculty of Nursing, Assiut University, Egypt. \\ 2. Professor of Medical- Surgical Nursing, Faculty of Nursing, Assiut University, Egypt \\ 3. Lecturer of Internal Medicine and Nephrology, Faculty of Medicine, Assiut University, Egypt. \\ 4. Lecturer of Medical, Surgical Nursing, Faculty of Nursing, Assiut University, Egypt.
}

\begin{abstract}
Quality of sleep is the satisfaction of sleep experience, integrating aspect of sleep initiation, sleep maintenance, sleep quantity, refreshment upon awakening and a well -recognized predictor of physical and mental health. This study aimed to assess quality of sleep in hemodialysis patients. Research design: This study is Descriptive research design. Sample: A convenience samples of (60) adult patients among regular hemodialysis, their age range between $(20-60)$ by Mean \pm SD 39.48 \pm 11 .75from both sexes and are willing to participate in the study. Setting: The study was conducted in Hemodialysis unit at Assiut University Hospital. Tools: Two tools were used: structured interview questionnaire and Sleep Quality Scale. Results: There were severe sleep disorders in hemodialysis patients. Conclusion: sleep affected by many factors that affect on quality of sleep in hemodialysis patients. Recommendations: In addition to medical treatment to eliminate sleep problems and increase their sleep quality, the implementation of sleep hygiene intervention could also be beneficial .Further researcher should focus on identifying new methods and treatments technique to improved sleep quality.
\end{abstract}

Key wards: Hemodialysis \& Quality of Sleep.

\section{Introduction}

Sleep is a naturally recurring state of mind and body, characterized by altered consciousness, relatively inhibited sensory activity, inhibition of nearly all voluntary muscles, and reduces interaction with surrounding. (Joiner \& William, 2016)

Sleep disorder is a condition characterized by disturbed sleep-related pattern or behaviors. The prevalence of sleep-related problems and disorders is high in patients with end-stage renal disease, particularly sleep apnea, restless legs syndrome, and overall poor sleep quality (Plantinga et al., 2011)

Humans may suffer from various sleep disorder. Including dipsomania such as insomnia, hypersomnia, narcolepsy and sleep apnea; parasomnias such as sleep walking and rapid eye movement (REM) behavior disorder and circadian rhythm sleep disorders. (Randall \& David, 2016)

Sleep disorders have appeared as an important health hazard and some of the factors involved in the pathogenesis of renal disease are the same that cause or are associated with sleep apnea. (Martin, 2011)The factors contributing to sleep disturbances in patients on dialysis have been classified as treatment related (e.g. premature discontinuation of dialysis, rapid changes in fluid and electrolyte and acid base balance, alteration in medications, dialysis shift); psychological (e.g. anxiety, depression, stress and worry); disease related (e.g. anemia, uremia and metabolic changes); life style related (e.g. excess coffee, smoking, poor sleep hygiene). (Merlino, et al., 2015)

Also sleep disorders are highly prevalent in hemodialysis patients, intensifying their individual and social problems to some extent despite many investigations on the prevalence of sleep disorders in hemodialysis patients (HD) and the associated factors. (Giordano et al., 2015)

Sleep is a basic physical requirement for maintaining physical and mental health, whose duration varies between 4 and 10 hours a day and can be influenced by emotional and general lifestyle factors. Poor Sleep Quality (SQ) can disturb patient's emotions, thoughts and motivation causing tiredness, difficulty to concentrate, loss of appetite, nervousness, anxiety and depression. (Koch et al., 2009)

Good sleep quality is defined subjectively as one's perception of falling asleep easily, getting sufficient duration so as to wake up felling rested, and making it through their day without experiencing excessive day time sleepiness.(Unruh, et al., 2014)

People who get enough quality sleep have more energy, better cognitive function, healthier immune systems, and improved memory, alertness, attentiveness and performance throughout the day. They are also in a better mood. They are better able to acquire and perfect new skills, connect new information with current knowledge, and manage pain as the analgesic aspects of sleep increase pain thresholds. (Fitch., et al., 2017) 


\section{Significance of the study}

From the researcher's clinical experience it has been observed that a lot of hemodialysis patients are in need for assessment quality of sleep. Therefore, this study will be help such group of patients how-to assess factors affect on sleep. Furthermore this study could be helpful for all renal failure patients undergoing hemodialysis.

\section{Aim of the study}

The aim of this study is to assess quality of sleep in patients undergoing hemodialysis.

\section{Research question}

What is quality of sleep assessment in patients undergoing hemodialysis?

\section{Patients \& Method}

\section{Research design}

Descriptive research design was used in this study.

\section{Sample}

Convenience samples of (60) adult patients on regular hemodialysis, their age range between (20 60 ) by Mean \pm SD $39.48 \pm 11.75$ from both sexes and are willing to participate in the study. The sample was 60 patients undergoing hemodialysis was selected by using the following equation according to Steven \&Thompson (2012)

$n=\frac{N \times p(1-p)}{\left.\left[N-1 \times\left(d^{2} \div z^{2}\right)\right]+p(1-p)\right]}$.

$\mathrm{N}=$ total patient population size of 120 patients who undergoing hemodialysis of Assiut university hospitals. During sessions by $n=120$ of hemodialysis patients during sessions. $Z=$ confidence levels is 0.95 and is equal to 1.96 . $\mathrm{D}=$ the error ratio is $=0.05 \mathrm{P}=$ the property availability ratio and neutral $=0.50$. Sampling was conducted at morning and evening shift. Respiratory disease patients and heart failure patients were excluded.

\section{Setting}

The study was conducted in Hemodialysis Unit at Assiut University Hospital.

\section{Study tools}

Two tools were used in this study and were developed by the researcher based on reviewing the relative national and international scientific literature as (Vafaei, \& Nobahar, 2017), (Davison, 2018), (Veterans, et al., 2016), (Lewis et al., 2015) (Chang, et al., 2015) \& (Ohayon., et al., 2017) Theses tools were used to assess quality of sleep in patients undergoing hemodialysis.

Tools

Two tools were utilized in this study

Tool (I): A structured interview questionnaire sheet: It was developed by the researcher based on references include the following parts:
Part 1: Demographic data included the following (age, sex, marital status, level of education, occupation and residence).

Part 2: Patient habits it included the following (smoking, drinking coffee or tea before sleep, taking medication for sleep, watching television, eating heavy meals before sleep and doing exercise before sleep)

Tool (II): Sleep Quality Scale (SQS) developed by (Howell et al., 2008) consisting of (28) items, the SQS evaluates six domains of sleep quality: daytime symptoms, restoration after sleep, problems initiating and maintaining sleep, difficulty waking, and sleep satisfaction).

\section{Scoring system}

Using a four point, Likert - type scale, respondents indicate how frequently they exhibit certain sleep behaviors $(0=$ "Rarely or few," $1=$ "some times," $2=$ "often," $3=$ "almost always").which every of them mean that:Rarely:None or 1-3 times a month, sometimes : 1-2 times a week, often:3-5 times a week and almost always:6-7 times a week. Scores on items belong to factors 2and 5(restoration after sleep and satisfaction with sleep) and are reversed before being tallied. Total scores can range from 0 to 84, with higher scores demoting more acute sleep problems. Sleep disorder divided into three category (Mild, Moderate and Severe) were graded as (0-28) mean mild sleep disorder, (28-56) moderate sleep disorder and (56-84) sever sleep disorder.

\section{Operational Design}

Technique for data collection

This study was carried out in three phase:

Field work:

The researcher reviewed related literature of the current study, local \& international, using text books, articles, and scientific magazines. The proposed study setting was assessed for the numbers of patients in Hemodialysis Unit at Assuit University Hospital. This phase ended by a pilot study.

\section{Content validity and reliability}

The content validity of study tools were checked by 3 expert professors in field of nursing and medicine they reviewed the instruments for clarity, relevance, comprehensiveness, understanding, applicability and easiness for administrative minor modifications that required correction was carried out accordingly. Content reliability refers to the degree of consistency with which the instrument (The questionnaire) measures the thing it is supposed to be measuring (Quality of sleep in patients undergoing hemodialysis). Reliability of tool was confirmed by Alpha cronbach test (0.95).

A pilot study

A pilot study carried out in April 2018 to test the feasibility and practicability of the study tools and 
conducted on $10 \%$ of the sample (6 patients) of sample. It had also provided an estimate of time needed to fill out the tools.

\section{Phase2:Planning phase}

Based on finding of the exploratory phase, the patient assessment sheet was developed by the researcher, after extensive literature review considering patients' needs and their levels of understanding.

\section{Phase3:Implementation phase}

Data were collected from Hemodialysis Unit at Assuit University Hospital for 3 months during the period from May 2018 to July 2018. The study was carried out at morning and afternoon shifts for all available patients.

At initial interview the researcher introduce herself to initiate line of communication, explain the nature and purpose of the study to the selected patients who are willing to participate in the study and fill out the questionnaire sheet Tool (1) to assess the demographic data and patients habits.

After assessment of the patients using the structured interviewing questionnaire sheet Tool (1) that filled through the researcher and then assess quality of sleep for patients by using Sleep Quality Scale (SQS) Tool (2) that filled through the researcher.

\section{Administrative Design}

An official Permission to carry out the study was obtained from the responsible hospital authorities of the Hemodialysis Unit at Assiut University Hospital. To achieve validity and reliability of tools, it will be reviewed by experts (medical and nursing) in the field of the study and necessary modifications will be done.

\section{Ethical considerations}

1. Research proposal was approved from Ethical Committee in the faculty of nursing.

2. There is no risk for study subject during application of research.

3. The study was following common ethical principles in clinical research.

4. Oral consent was obtained from patients or guidance who are willing to participate in the study, after explaining the nature and purpose of the study.

5. Confidentiality and anonymity will be assured.

6. Study subject have the right to refuse to participate and or withdraw from the study without any rational any time.

7. Study subject privacy was considered during collection of data.

\section{The statistical design}

The data obtained had reviewed, prepared for computer entry, coded, analyzed and tabulated, Descriptive statistics include (frequencies and percentages, mean and standard deviation test were done using computer program (SPSS). 


\section{Results}

Part I. Description of study sample according to demographic characteristics.

Table (1): Distributions of demographic characteristics for the study sample (n=60)

\begin{tabular}{|c|c|c|}
\hline Variables & No & $\%$ \\
\hline \multicolumn{3}{|l|}{ Age (years) } \\
\hline $20-30$ & 9 & 15.0 \\
\hline $30-40$ & 22 & 36.7 \\
\hline $40-50$ & 9 & 15.0 \\
\hline $50-60$ & 20 & 33.3 \\
\hline Mean \pm SD & \multicolumn{2}{|c|}{$39.48 \pm 11.75$} \\
\hline \multicolumn{3}{|l|}{ Sex } \\
\hline Male & 30 & 50.0 \\
\hline Female & 30 & 50.0 \\
\hline \multicolumn{3}{|l|}{ Marital status } \\
\hline Single & 11 & 18.3 \\
\hline Married & 47 & 78.3 \\
\hline Widow & 2 & 3.3 \\
\hline \multicolumn{3}{|l|}{ Educational level } \\
\hline Illiterate & 11 & 18.3 \\
\hline Read and write & 12 & 20.0 \\
\hline Primary & 10 & 16.7 \\
\hline Secondary & 21 & 35.0 \\
\hline Higher education & 6 & 10.0 \\
\hline \multicolumn{3}{|l|}{ Occupation } \\
\hline Work & 13 & 21.7 \\
\hline Not work & 47 & 78.3 \\
\hline \multicolumn{3}{|l|}{ Residence } \\
\hline Urban & 20 & 33.3 \\
\hline Rural & 40 & 66.7 \\
\hline
\end{tabular}

Part II. Description of study sample according to patients habits.

Table (2): Percentage distribution regarding patients habits of the study sample $(n=60)$

\begin{tabular}{|l|c|c|c|c|}
\hline \multicolumn{1}{|c|}{ Variables } & \multicolumn{2}{c|}{ Yes } & \multicolumn{2}{c|}{ No } \\
\cline { 2 - 5 } \multicolumn{1}{|c|}{} & $\mathrm{N}$ & $\%$ & $\mathrm{~N}$ & $\%$ \\
\hline B- Assessment of patient habits & \multicolumn{4}{c|}{} \\
\hline Smoking & 11 & 18.3 & 49 & 81.7 \\
\hline Drinking coffee or tea before sleep & 31 & 51.7 & 29 & 48.3 \\
\hline Taking medication for sleep & 4 & 6.7 & 56 & 93.3 \\
\hline Watching Television & 47 & 78.3 & 13 & 21.7 \\
\hline Eating heavy meals before sleep & 17 & 28.3 & 43 & 71.7 \\
\hline Doing exercise before sleep & 16 & 26.7 & 44 & 73.3 \\
\hline
\end{tabular}

Table (3): Distribution of sleep quality domains of the study sample (n=60)

\begin{tabular}{|l|l|}
\hline \multicolumn{1}{|c|}{ Sleep Quality Domains } & \multicolumn{1}{c|}{ Mean \pm SD } \\
\hline Daytime dysfunction & $12.3833 \pm 2.66230$ \\
\hline Restoration after sleep & $14.7667 \pm 2.80052$ \\
\hline Difficult y in falling sleep & $37.8167 \pm 7.91585$ \\
\hline Difficult y in getting up & $16.9000 \pm 3.21912$ \\
\hline Satisfaction with sleep & $14.1667 \pm 2.46444$ \\
\hline Difficulty in maintaining sleep & $16.9000 \pm 3.21912$ \\
\hline
\end{tabular}

Vol , (7) No, (17) June, 2019 
Table (4): Degree of sleep disorder of the study sample ( $n=60)$

\begin{tabular}{|l|c|c|}
\hline \multicolumn{1}{|c|}{ Sleep disorder } & N & \% \\
\hline Mild & 0 & $0.0 \%$ \\
\hline Moderate & 9 & $15.0 \%$ \\
\hline Severe & 51 & $85.0 \%$ \\
\hline Total & 60 & $100 \%$ \\
\hline
\end{tabular}

Table (1): Reveals that there was equal percentage for male and female of the studied sample, the highest percentage of the studied sample (78.3\%) were married, their age ranged from (30 to 40) years old $(36.7 \%)$ by Mean \pm SD $39.48 \pm 11.75$, regarding to level of education about $(35 \%)$ were Secondary school, also the majority of them were not working (78.3\%), and living in rural. (66.7\%)

Table (2): Reveals that regarding distribution of patient habits for the study sample the majority of them $(78.3 \%)$ were watching television, the half of them were drinking coffee or tea before sleep $(51.7 \%)$, the third of them were eating heavy meals before sleep $(28.3 \%)$ and doing exercise before sleep (26.7\%)

Were less than third of the studied sample were smoking (18.3\%),

Table (3): Reveals that regarding distribution of domains of sleep quality for the study sample the majority of them having difficulty in falling sleep (37.8167 \pm 7.91585$)$.

Table (3): Illustrated that regarding degree of sleep disorder for the study sample the majority of them have severe sleep disorder $(85.0 \%)$.

\section{Discussion}

Hemodialysis is associated with an increased prevalence of sleep disturbance. Which have a major influence on vitality and general health of patients (Parker, 2015)

As we sleep, our brain "prunes" out unnecessary information and the space between brain cells expands, allowing the brain to flush out waste that accumulates when we are awake. The buildup of toxins in the brain is linked to neurodegenerative disorders, Sleep involves the most powerful set of processes in the body when we let it happen naturally. Unfortunately, many of us put barriers in the way of sleep and then struggle with the consequences. (Ohayon., et al., 2017)

The aim of this study is to assess quality of sleep in patients undergoing hemodialysis

The present study revealed that, the majority of the studied patients were married, more than half of them living in rural area and their age ranged from (30 to 40) years old. This result agree with
(Maryam, et al., 2014) who found that the majority of the participants was married, the mean age of the participants was $45.12+15.86$ years. And with (Tel \& Esmek, 2012) who found that more than half of the patients were from rural areas.

The current study revealed that the highest presented regarding distribution of the patients habits for the study sample the majority were watching television and the half of them drinking coffee or tea before sleep. This result agree with (Elizabeth \& Cespedes, 2014) who found that greater television viewing and bedroom television were associated with decreased sleep duration. And agree with (Exelmans, et al., 2017) who found that watching or regular viewing before bed effect on sleep. And agree with ( Clark \& Landolt, 2017 ) who found that sleep complaints high in patient with increased caffeine intake and lead to prolonged sleep latency, shorter total sleep time, worsening of perceived sleep quality, increase light sleep and shortening deep sleep time as well as frequent awakening.

Our study show that regarding distribution of sleep quality domains of the study sample the majority were having difficulty in falling sleep. This result agree with (Doghramji, 2016) who found that that commonly patients undergoing hemodialysis have difficulty in falling asleep.

Finally, this study indicated that the majority of the study sample have sleep disorder. This result agree with (Iliescu, et al., 2012) who found that a large percent of hemodialysis patients suffer from poor sleep.

\section{Conclusion}

According to the present study poor sleep quality is a common problem and there was high sleep disorder and affected by many factors among hemodialysis patient in Hemodialysis Unit at Assiut University Hospital.

\section{Recommendations}

In the light of the findings of the current study the following recommendations were suggested:-

Recommendation for patients

In-service training programs related to sleep hygiene teaching for hemodialysis patients must be 
frequently conducted in the unit for continuous maintain and improve sleep quality.

\section{Recommendations for future researches}

1- A designed sleep hygiene teaching protocol to improve quality of sleep for hemodialysis patients.

2- Management of sleep quality is important care giving to hemodialysis patients.

3- Further researches should be done on a large sample to generalize the result of the study.

\section{References}

1. Clark, I., \& Landolt, H., (2017): Coffee, Caffeine and sleep disturbance, Journal of Geophysical research, vol. (31) No.(2) Pp. 70-78.

2. Chang, Anne-Marie; Aeschbah, Daniel: Duffy, Jeanne F., Czisler, Charles A., (2015): Evening use light -emitting Readers negatively affects sleep, circadian timing and next morning alterness , Jelin Sleep Med, vol.(12) N0.(4) Pp. 1232- 1237.

3. Davison, S., (2018): End-of-life care preferences and needs: Perceptions of patients with chronic kidney disease, Clin. J. Am. Soc. Nephrol, vol. (5) No. (7) Pp. 195-204.

4. Doghramji, K.. (2016): Insomnia and excessive day time sleepiness. Journal of clinical psychiatry, vol. (64) No.(4) Pp. 24-9.

5. Elizabeth M., \& Cespedes (2014): Television viewing, bed room television and sleep duration, Journal. Of Medicine, vol. (13) No. (5) Pp. 1163- 1171.

6. Exelmans L., Van den, \& Bulck J., (2017): Binge viewing television before sleep and the role of pre- sleep arousal, Jelin Sleep Med, vol. (13) No. (8) Pp. 1001- 1008.

7. Fitch K., Bernstein S., Aguilar M., Burnand B., \& LaCalle J., (2017): sleep and sleep quality, Jelin Sleep Med, vol. (2) No. (1) Pp. 141-158.

8. Giordano M., Ciarambino T., Pace M., Passavanti M., Viggiano A., \& Paolisso G., (2015): Relationship between Pain Tolerance, Sleep Disorders and Quality of Life in Elderly Diabetic Haemodialysis Patients. Int J Nephrol Kidney Failure, vol. (3) No. (1) Pp. 1-4.

9. Howell, A., Digdon, N., Buro, K., \& Sheptycki, A., (2008). Relations among mindfulness, wellbeing, and sleep. Personality and Individual Differences No. (45) Pp. 773-777.

10. Iliescu E., Coo H., McMurray M., Meerscl, Quinn M., \& Singer M., (2012): Quality of sleep and health related quality of life in hemodialysis patients. Nephral Dial Transplant, vol.(18) No.(1) Pp. 126-32.

11. Joiner W., and William J., (2016): Unraveling the Evolutionary Determinants of sleep, journal of Neuro science vol. (26) No. (20) Pp. 10-73.

12. Koch B., Nagtegaal J., Kerkhof G., \& Wee P., (2009): Circadian sleep-wake rhythm disturbances in end-stage renal disease, Clin. J. Am. Soc. Nephrol, vol. (2) No. (2) Pp. 1-155.

13. Lewis, Sharon L., Shannon Ruff Dirksen, Margaret Mclean, Heike per, \& Linda Bucher, (2015): Lewis's Medical - Surgical Nursing: Assessment and Management of clinical problems, Chapter8 (2end edition)Haryana, India. Pp. 96.

14. Martin, J., (2011): Assessment and treatment of sleep disturbances in older adults Clinical Psychology Review, vol. (20) No. (6) Pp. 783805.

15. Maryam S., Soheila S., Poran V., \& Farshid H., (2014): Sleep hygiene training program for patients on hemodialysis, Jn. Of Medicine, vol .(8) No. (1) Pp. 67.

16. Merlino G., Gigli G., \& Valente M., (2015): sleep disturbances in dialysis patients, vol. (4) Issue (2) Pp.66-70.

17. Ohayon M., Carskadon M., Guilleminault C., \& Vitiello M., (2017): Meta-analysis of quantitative sleep parameters from childhood to old age in healthy individuals: developing normative sleep values across the human lifespan. Sleep, Journal of the American Society of Nephrology, vol. (27) No. (3) Pp. 1255-1274.

18. Parker K., (2015): Sleep disturbance in dialysis patients, Nephrourol Monthly Journal, vol. (7) No. (2) Pp. 131-143.

19. Plantinga L., Lee K, Inker L., Saran R., Yee J., \& Gillespie B., (2011): Association of sleeprelated problems with CKD in the United States, Kidney Dis, vol. (58) No. (4) Pp. 554-64.

20. Randall, \& David K., (2016): How the light bulb disturbed our sleeping pattern and change the world, Journal of Clinical Nursing, vol.(6) No.(2) Pp. 567-89.

21.Steven K., \& Thompson (2012): sample size , Pp. 59-60

22. Tel H, \& Esmek M., (2012): Quality of sleep in hemodialysis patients, Clin. J. Am. Soc. Nephrol, vol. (36) No.(9) Pp. 479-86.

23. Unruh M., Hartunian M., Chapman M., \& Jaber B., (2014): sleep quality and clinical correlates in patients on maintenance dialysis. Clin Nephrol, vol. (59) No. (4) Pp. 280-8. 
24. Vafaei, A., Nobahar, M., (2017): The care preferences of patients under hemodialysis, Journal of Clinical Nursing, vol. (6) No. (2) Pp. 210-215.

25. Veterans G., Wong J., Vilar E., Farrington K., (2016): Health Administration Warning System. Hemodialysis Medicine, Bleeding Episodes during dialysis, Journal of Clinical Nursing, vol.

(4) No.(2) Pp. 478-483. 